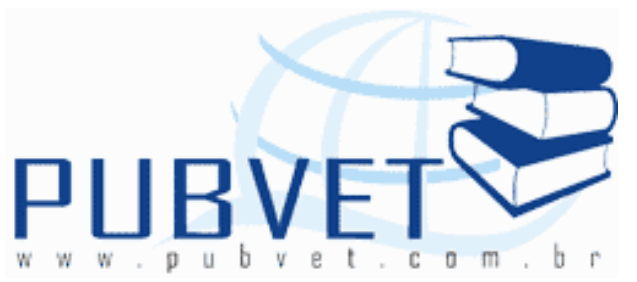

PUBVET, Publicações em Medicina Veterinária e Zootecnia.

\title{
Afecção oftálmica periocular causada por Pseudomonas sp em Amazona aestiva - relato de caso
}

\author{
Catarina Rafaela Alves da Silva ${ }^{1}$; Francisco Lima Silva ${ }^{2}$; Marcos Daniel de \\ Sousa Ferreira ${ }^{1}$; Deyse Naira Mascarenhas Costa $^{1}$ \\ ${ }^{1}$ Pós Graduação em Ciência Animal-UFPI \\ ${ }^{2}$ Professor Doutor Universidade Federal do Piauí
}

\section{Resumo}

Inúmeras são as doenças bacterianas que afetam as aves ornamentais, sejam como agentes primários ou secundários. Nas aves as bactérias Gram negativas são consideradas as mais patogênicas, dentre estas, destacam-se as Pseudomonas sp que são normalmente encontradas em pequenas quantidades em culturas realizadas com amostras de coanas e cloaca de aves. Entretanto, quando é encontrada fora do trato gastrointestinal ou da região coana/orofaringe pode-se tornar um perigoso agente patogênico. O diagnóstico foi feito através do isolamento e identificação do agente patogênico Pseudomonas sp. Para o tratamento desta enfermidade empregou-se o uso do antiinflamatório Meloxicam, do antibiótico Enrofloxacina, do colírio antibacteriano Tobramicina, além do uso destes medicamentos administrou-se $2 \mathrm{ml}$ de Glicose por via oral. Ao final do tratamento observou-se uma melhora do estado geral do animal, com a parada de secreção nasal, da diarréia e regressão do processo inflamatório no olho direito do animal. Considerando os 
SILVA, C.R.A. et al. Afecção oftálmica periocular causada por Pseudomonas sp em Amazona aestiva - relato de caso. PUBVET, Londrina, V. 6, N. 2, Ed. 189, Art. 1275, 2012.

resultados obtidos, concluiu-se que o tratamento realizado foi eficiente para a cura do animal.

Palavras-chave: Psitacídeos, Oftamologia, Infecção bacteriana.

\title{
Ophthalmic periocular disease caused by Pseudomonas sp in Amazona aestiva - case report
}

\begin{abstract}
There are numerous bacterial diseases affecting ornamental birds, whether as the primary or secondary. In birds Gram negative bacteria are considered the most pathogenic among these, there are the Pseudomonas $\mathrm{sp}$ which are normally found in small amounts in cultures performed with samples from choanal and cloacal swabs from birds. However, when it is found outside the gastrointestinal tract or region of the choana / oropharynx can become a dangerous pathogen. The diagnosis was made by isolation and identification of the pathogen Pseudomonas sp. For the treatment of this disease has employed the use of anti-inflammatory Meloxicam, the antibiotic Enrofloxacin antibacterial Tobramycin eye drops, and the use of these drugs was administered $2 \mathrm{ml}$ of glucose orally. At the end of treatment there was a general improvement of the animal, with the parade of runny nose, diarrhea and regression of the inflammatory process in the right eye of the animal. Considering these results, we concluded that the treatment was effective in the cure of the animal.
\end{abstract}

Keywords: Parrots, ophthalmologists, bacterial infection.

\section{REVISÃO DE LITERATURA}

Ao longo do tempo, os animais selvagens, e principalmente as aves, estão se tornando mais populares como animais de companhia, devido a sua beleza em cantos e cores (GONDIM et al., 2006). Entre as muitas espécies de aves, existe um grande número delas que se pode ter como animais de estimação familiar. Exemplos de espécies famosas que vivem freqüentemente 
SILVA, C.R.A. et al. Afecção oftálmica periocular causada por Pseudomonas sp em Amazona aestiva - relato de caso. PUBVET, Londrina, V. 6, N. 2, Ed. 189, Art. 1275, 2012.

como animais de estimação são os papagaios, cacatuas, araras e um grande número de espécies de periquitos (VERHALLEN, 2000).

A rotina na clínica de aves é basicamente emergencial, e entre as causas mais comumente relatadas de enfermidades nas aves de estimação estão as patologias do trato respiratório, destacando-se dentre estas as doenças de origem bacteriana (RUPLEY, 1999).

A necessidade dos profissionais da área de veterinária em instruírem-se a respeito de tais animais se torna, deste modo, crucial (SCHULTE; RUPLEY, 2004).

Este trabalho objetivou relatar o tratamento de um caso de afecção oftálmica periocular causada por Pseudomonas sp em Amazona aestiva atendido na Clínica Animal's da cidade de Teresina-Piauí.

\section{DESCRIÇÃO DO CASO}

O presente trabalho relata a ocorrência de infecção causada por Pseudomonas sp em um Papagaio verdadeiro (Amazona aestiva), adulto, atendido no Hospital Veterinário Universitário da Universidade Federal do Piauí (HVU-UFPI), apresentando histórico de espirros, regurgitação, diarréia, sonolência e inchaço ao redor do olho direito. Ao exame físico observou-se que o animal apresentava secreção nasal, e uma área destituída de penas na sua hemiface direita na região periocular com presença de foco inflamatório, de onde foi retirado um material caseoso para a realização de exame microbiológico (figura 1).

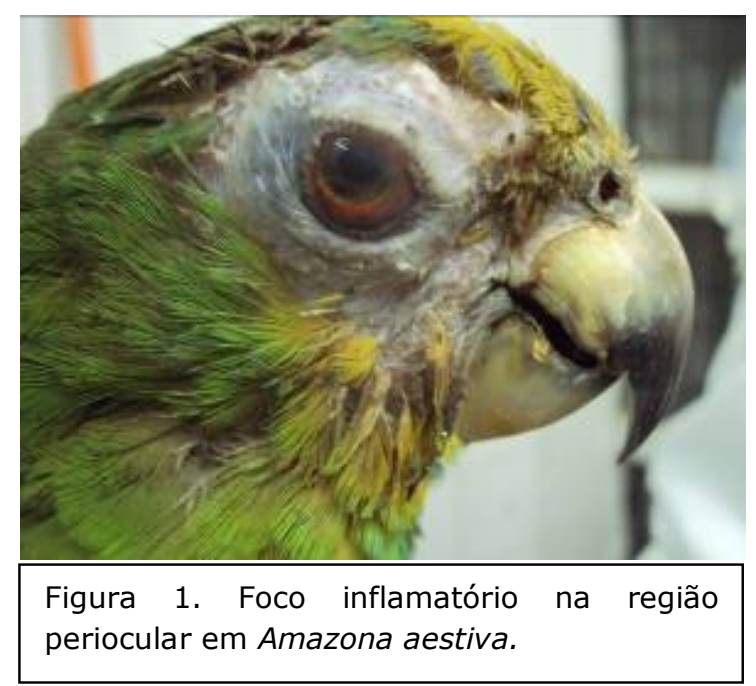


O diagnóstico foi feito através do isolamento e identificação do agente patogênico Pseudomonas sp. Para o tratamento desta enfermidade empregouse o uso do antiinflamatório Meloxicam 0,5 mg (0,2mg/kg/VO/SID) durante 4 dias, do antibiótico Enrofloxacina 50mg (20 mg/kg/VO/BID) durante 8 dias, do colírio antibacteriano Tobramicina $3 \mathrm{mg}$ ( 2 gotas no olho direito 3 vezes ao dia durante 8 dias), e do vermífugo Mebendazol Suspensão ( $25 \mathrm{mg} / \mathrm{kg} / \mathrm{VO} / \mathrm{SID}$ ) durante 4 dias, além do uso destes medicamentos administrou-se $2 \mathrm{ml}$ de Glicose $50 \%$ por via oral durante 5 dias.

\section{DISCUSSÃO E CONCLUSÃO}

As bactérias são microrganismos amplamente distribuídos na natureza, sendo encontradas tanto no ambiente quanto na microbiota natural do corpo das aves. Muitas delas são de grande importância para o funcionamento normal do organismo destes animais. Porém, até mesmo estas bactérias componentes da microbiota natural, em condições específicas, podem levar ao desenvolvimento de uma patologia (RUPLEY,1999; DE CARVALHO, 2004).

Nas aves as bactérias Gram negativas são consideradas as mais patogênicas, dentre estas, destacam-se as Pseudomonas $\mathrm{sp}$ que são normalmente encontradas em pequenas quantidades em culturas realizadas com amostras de coanas e cloaca de aves. Entretanto, quando é encontrada fora do trato gastrointestinal ou da região coana/orofaringe pode-se tornar um perigoso agente patogênico (BROWN, 2000; CUBAS, 2006).

Surtos de infecção causados por Pseudomonas aeruginosa ocorrem quando o suprimento de água é contaminado por material orgânico, permitindo assim que a bateria se desenvolva na água de beber das aves (BROWN, 2000).

Em psitacídeos a infecção por estas bactérias está comumente associada a enfermidades do trato respiratório superior, podendo causar pneumonia, aerossaculite e broncopneumonia, principalmente em aves imunossuprimidas ou que apresentem algum tipo de deficiência nutricional podem desenvolver um quadro de enterite catarral e hemorrágica. As aves 
SILVA, C.R.A. et al. Afecção oftálmica periocular causada por Pseudomonas sp em Amazona aestiva - relato de caso. PUBVET, Londrina, V. 6, N. 2, Ed. 189, Art. 1275, 2012.

acometidas podem apresentar espirros, secreção nasal, dispnéia, regurgitação, sonolência, automutilação e diarréia (CUBAS, 2006).

Ao final do tratamento observou-se uma melhora do estado geral do animal, com a parada de secreção nasal, da diarréia e regressão do processo inflamatório no olho direito do animal. Considerando os resultados obtidos, concluiu-se que o tratamento realizado foi eficiente para a cura do animal.

\section{REFERÊNCIAS}

BROWN, N. H. H. Psittacine birds. In: _ TULLY, JR, T. N.; LAWTON, M. P. C.;DORRESTEIN, G. M. Avian medicine. Oxford: Reed Educational and Professional Publishing Ltda, 2000.

CUBAS, Z. S.; SILVA, J. C. R.; CATÃO-DIAS, J. L. Tratado de animais selvagens medicina veterinária. São Paulo: Roca, 2006.

DE CARVALHO, P. P. Alterações patológicas encontradas em psitacídeos mortos em cativeiro de janeiro de 1994 a dezembro de 2002 no estado do Paraná. 2004. 43f. Dissertação (Mestrado em Ciências Veterinárias). Curso de Pós-Graduação em Ciências Veterinárias, Setor de Ciências Agrárias, Universidade Federal do Paraná.

GONDIM L.S.Q., GOMES D.M.;MAIA P.C.C. Casuística de aves selvagens atendidas de 2002 a 2004 na Escola de Medicina Veterinária da Universidade Federal da Bahia. $26^{\circ}$ Congr. Bras. Zoologia, Londrina, p.86-87; 2006.

RUPLEY, A. E. Manual de clínica aviária. São Paulo: Roca LTDA, 1999.

SCHULTE M.S.;RUPLEY A.E. Avian care and husbandry. Vet. Clin. North Am. Exot. Anim. Pract. n.7;v.2,p.315-350; 2004.

VERHALLEN, E. V. Enciclopédia das Aves de Gaiola. Livros e Livros, 2000. 